\title{
Alguns problemas do nosso ensino superior
}

\author{
ALBERTO CARVALHO DA SILVA
}

$\mathrm{O}$ NOSSO ENSINO superior, $68,4 \%$ em universidades, enfrenta sérios problemas e desafios; as grandes diferenças regionais, a pressão por aumento de vagas, a contribuição para o desenvolvimento tecnológico e inovação, a necessidade de expansão e atualização da pesquisa, a elevação dos padrões de qualidade, os custos elevados e a conquista da autonomia didático-administrativa e financeira são suficientes para dar uma idéia das dificuldades que precisam ser enfrentadas a curto prazo se se quiser evitar uma decadência que, para muitos, já é visível. Enquanto essa decadência pode ocorrer a passos rápidos, a recuperação é um processo lento, caro e incerto. Neste trabalho procura-se abordar alguns desses aspectos.

\section{Preâmbulo}

A preocupação com o ensino superior no Brasil começou no século XIX com a organização de escolas profissionais (Dantes, 1980). As duas primeiras universidades - no Paraná e no Rio de Janeiro - formadas entre 1910 e 1920, resultaram da reunião de escolas isoladas pré-existentes. Na década de 20 , sob a influência da Associação Brasileira de Educação e da Academia Brasileira de Ciências, desenvolveu-se amplo debate sobre ensino estabelecendo-se que caberia às Universidades, além de manter escolas para formar profissionais a serviço da Sociedade, promover o desenvolvimento da ciência e da cultura, usufruindo de autonomia tanto nas atividades didáticas, científicas e culturais que desenvolveriam como em sua administração.

No início da década de 30 foi criado, pelo governo Vargas, o Ministério da Educação e Saúde e implantada uma reforma da educação (1) estabelecendo que o ensino superior poderia ser oferecido em universidades e institutos isolados, particulares ou oficiais, mantidos por governo federal e por estados (Sampaio, 1991). Além das escolas profissionais cada universidade deveria incluir uma "Faculdade de Educação e Letras que teria como seus principais objetivos", a formação de professores para o ensino secundário e a promoção da ciência. O corpo docente das universidades era formado por professores catedráticos vitalícios escolhidos mediante concurso de títulos e provas e auxiliados por assistentes indicados por eles, e por eles demissíveis ad nutum. A Universidade de São Paulo, instituída em 1934, incluía uma "Faculdade de Filosofia, Ciências e Letras" que, 
contando com um excelente elenco de professores contratados no exterior, cumpriu fielmente os objetivos da "reforma" tanto na formação de professores quanto no desenvolvimento da pesquisa nas diversas áreas do conhecimento.

O número de instituições de ensino superior aumentou rapidamente nos anos seguintes alcançando, em 1960, 247 escolas públicas e 103 particulares. No mesmo período o número de matrículas passou de 26.761 para 93.202, mas ainda menos de um aluno por mil habitantes.

Considerava-se como responsabilidade das universidades elevar os seus padrões de ensino e promover o desenvolvimento da ciência. As primeiras agências oficiais em apoio à pesquisa, ao aperfeiçoamento de docentes e à formação de pesquisadores surgiram apenas em 1951, com a criação do Conselho Nacional de Pesquisa (CNPq) e da Coordenação do Aperfeiçoamento do Pessoal de Nível Superior (CAPES). Em São Paulo essa iniciativa foi precedida pelos Fundos Universitários de Pesquisa na USP em 1942, e pela previsão da Fapesp na Constituição Estadual de 1947, mas os "fundos" foram transitórios e a Fapesp só foi instalada em 1960.

\section{Os anos 60}

A partir de 1960 e principalmente a partir do governo militar em 1964, procurou-se criar os fundamentos de uma política de ciência e tecnologia tomando como base as universidades públicas e os institutos públicos de pesquisa. Em 1962 foi criado o Fundo do Desenvolvimento Técnico-Científico (FUNTEC), com 3\% do orçamento do BNDE, apoiando as primeiras iniciativas em pós-graduação na COPPE/UFRJ. Em 1967 foi instituída a Finep que, a partir de 1971, passou a gerir o Fundo Nacional de Desenvolvimento Científico e Tecnológico (FNDCT), criado em 1969. Em 1968 foi institucionalizada a pós-graduação stricto sensu. A partir de 1970 os Planos Estratégicos do Desenvolvimento Econômico (PEDs) passaram a dar destaque a ciência e tecnologia. Em 1974 foi concebido o Sistema Nacional do Desenvolvimento Científico e Tecnológico (SNDCT), seguido dos Planos Básicos do Desenvolvimento Científico e Tecnológico (PBDCTs) geridos pelo CNPq, devidamente reformulado e contando com um Programa de Avaliação e Perspectivas (Ferreira, 1993). Nos estados, além da Fapesp que iniciou atividades em 1962, foram instituídas a Fapergs em 1964, a Faperj em 1980 e a Fapemig em 1986 (Carvalho da Silva, 2000).

A par dessas medidas e em resposta às pressões da sociedade por aumento de vagas (crise dos excedentes), entre 1968 e 1971 foram criadas 17 novas universidades públicas (nove federais, seis estaduais e duas municipais) e entre 1968 e 1975, 10 universidades privadas, embora nem de longe se contasse com uma reserva de docentes para atender a uma expansão tão acelerada. Em 1980 já se tinha um total de 882 instituições de ensino superior. Destas, 200 eram públicas 
(45 universidades, uma federação de escolas integradas e 154 estabelecimentos isolados) e 689 entidades privadas (20 universidades, 19 federações integradas e 643 estabelecimentos isolados). O total de matrículas, que em 1964 fora de 142.386,

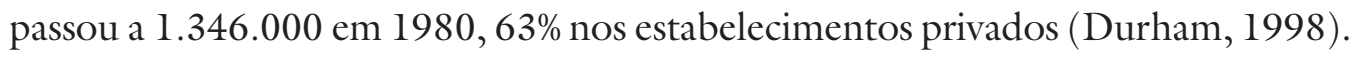

A expansão acelerada do número de estabelecimentos e matrículas foi facilitada pela excessiva tolerância no julgamento das propostas para credenciamento de novos estabelecimentos por parte do Conselho Federal de Educação (CFE) que, a partir de 1962, substituiu o Conselho Nacional de Educação (CNE) criado na reforma dos anos 30. Embora a função do CFE fosse consultiva, ele acabou por tomar decisões aprovando, até 1974, significativa parte das propostas submetidas a julgamento. A partir desse ano o Departamento de Assuntos Universitários (DAU) assumiu uma função central na formulação e conclusão da política de ensino superior interferindo, por meio de suas análises, com a liberalidade do CFE. Em 1977 novos credenciamentos foram suspensos e retomados em 1978, mas com um índice de aprovação da ordem de $10 \%$ dos pedidos examinados (Klein, 1992).

\section{A Reforma de 1968}

Já na década de 60 começava a evidenciar-se que a concepção da carreira docente e a organização da universidade não se ajustavam ao desenvolvimento científico e à expansão do ensino superior. O sistema autoritário da cátedra vitalícia fechava oportunidades de carreira e não estimulava cooperação entre as várias disciplinas, cada vez mais essenciais ao desenvolvimento científico e tecnológico; a repetição das mesmas cadeiras básicas em várias unidades resultava em uma multiplicação de instalações e de docentes trabalhando isoladamente na mesma disciplina com grandes diferenças em recursos e desempenho.

Esta situação culminou com a reforma aprovada pelo governo federal em 1968 estabelecendo, entre outras, as seguintes inovações:

- abolição da cátedra vitalícia;

- implantação do sistema de institutos em substituição a faculdades;

- instituição do departamento como unidade mínima de ensino e pesquisa;

- organização do currículo em etapas básica e de formação profissional;

- flexibilidade do currículo e sistema de créditos;

- criação de colegiados horizontais.

A cassação de vários líderes acadêmicos que atuavam na "reforma" e os exacerbados antagonismos e preconceitos que caracterizaram esse período resultaram em deformações em sua implantação. Só para ilustrar, podem ser citadas algumas diferenças entre os estatutos aprovados para a Universidade de São 
Paulo em 25 de abril de 1969, quatro dias antes da aplicação do AI-5 a 24 professores da universidade, inclusive o vice-reitor em exercício, e o que veio a ser aprovado em 21 de outubro do mesmo ano (Carvalho da Silva, 1997):

- recusaram-se os campi propostos para os novos centros da universidade no interior do estado;

- em vez de 30 institutos, a universidade voltou a ser formada por 15 faculdades, 7 escolas e 10 institutos;

- em vez de uma Câmara Curricular para elaboração e aprovação dos currículos básicos e profissionais, criou-se um Conselho de Ensino, Pesquisa e Extensão à Comunidade;

- a aceitação de especialistas de reconhecido valor mas não-docentes em concurso para professor titular ficou sujeita à aprovação por um mínimo de dois terços da congregação da unidade;

- em vez de "Dedicação à Universidade" como regime único de trabalho dos docentes, foram mantidos os regimes de tempo parcial, turno completo e dedicação exclusiva.

Apesar de a reforma de 1968 ter estabelecido uma carreira universitária aberta e baseada no mérito acadêmico, a escassez de pessoal qualificado e os critérios clientelistas que predominaram durante esse período contribuíram para que, tanto em qualidade de ensino quanto em produtividade em pesquisa, os resultados da reforma ficassem muito aquém das expectativas. Houve considerável aumento de investimento em pessoal que, nas universidades federais, em moeda de 1984, passou de Cr\$ 459 bilhões em 1972 para Cr\$ 1.017 bilhões, em $1976 \mathrm{e}$ Cr\$ 1.491 bilhões em 1980, mas boa parte desse aumento foi absorvida por mudanças no regime de trabalho e outros benefícios, e não por expansão e renovação do corpo docente. Todavia a pós-graduação evoluiu rapidamente de 135 cursos em 1969, um ano após a sua implantação, para 974 em 1979, com 32,3 mil alunos em mestrado e 3.971 em doutorado, contando com 4.003 mestres e 405 doutores já titulados.

\section{A década perdida}

A crise econômica dos anos 80 e as incertezas criadas pelos altos índices de inflação refletiram-se no ensino superior. O número de inscrições em exame vestibular baixou de 1,8 milhões em 1980 para 1,5 milhões em 1985, voltando a 1,8 milhões em 1989; o número total de vagas aumentou apenas de $404.814 \mathrm{em}$ 1980 para 466.794 em 1989; o número de matrículas foi 1.377 .286 em 1980 e 1.367.609 em 1985, chegando a 1.518.904 em 1989, um crescimento inferior ao da população (MEC/INEP, 2000). Durante esse período o sistema privado implantou 19 universidades e aumentou em $43,6 \%$ as suas matrículas e em $57 \%$ a 
sua oferta de vagas; o sistema público instituiu dez universidades (uma federal, sete estaduais e duas municipais) aumentando as matrículas em $13,7 \%$ e as vagas em 10,2\% graças a estados e municípios, uma vez que a rede federal se manteve paralisada. Apesar de tal paralisia do sistema federal, a sua despesa com pessoal nas instituições de ensino superior mais do que duplicou entre 1980 e 1990 (O estado atual..., 1994). Nas universidades federais o número de docentes aumentou em apenas 3,8\%, mas os docentes em tempo integral passaram de $20 \%$ no final dos anos 70 para $81 \%$ em 1989.

A situação de crise desencadeou maior movimentação da comunidade científica principalmente por meio da Academia Brasileira de Ciências, da Sociedade Brasileira para o Progresso da Ciência (SBPC) e da Associação Nacional dos Docentes de Ensino Superior (ANDES), convergindo para dois focos que ofereciam boas perspectivas de renovação: a implantação do Ministério de Ciência e Tecnologia em 1985, do qual se esperava grande dinamismo e inovação na política nacional de pesquisa aplicada; e a Assembléia Nacional Constituinte de 1987, que oferecia oportunidades de diálogo e discussão de propostas em favor da atividade científica e da educação em todos os seus níveis.

Em novembro de 1985 uma comissão de docentes indicada pelas sociedades científicas elaborou um documento a ser discutido na $37^{\text {a }}$ reunião anual da SBPC, antes de ser apresentado ao novo Ministério. Após uma análise da situação abrangendo as universidades e institutos de pesquisa, as estruturas de apoio ao desenvolvimento científico e tecnológico, os gastos públicos em ciência e tecnologia e a assimetria no desenvolvimento regional em ensino, pesquisa e pós-graduação, o documento concluía por uma série de recomendações, entre as quais a do Ministério de Ciência e Tecnologia associar-se ao Ministério da Educação na busca de soluções para os problemas enfrentados pelas universidades públicas, tanto em nível de graduação quanto de pós-graduação. Destacava-se também a necessidade de reformular a carreira do magistério superior tomando-se o mérito científico e a atividade docente como base para promoção e protelando-se a estabilidade no cargo até a comprovação de eficácia em ensino e pesquisa. Em novo relatório, elaborado três anos depois e discutido na $40^{\text {a }}$ reunião anual da SBPC em 1989, reconheciam-se algumas medidas positivas mas considerava-se que a situação era "ainda mais angustiosa e difícil para a ciência e tecnologia brasileira do que três anos atrás"; havia sido mantida a promoção por tempo de serviço até professor adjunto; fora proibida a contratação de novos professores; o ensino privado se deteriorava rapidamente face ao conflito entre seus custos crescentes e a perda progressiva de renda da população; os gastos nacionais em ciência e tecnologia haviam sofrido grandes variações de ano a ano passando, em valores de 1983, de US\$ 2 bilhões em 1980 para US\$ 4,3 em 1981 e US\$ 4,5 em 1982, baixando para US\$ 3,5 bilhões em 1983, US\$ 2,7 em 1984 e US\$ 2,4 em 1985, subindo novamente para US\$3,7 bilhões em 1986 e US\$ 3,8 em 1987 e baixando outra vez para US\$ 3,5 bilhões em 1988. 
Quanto à ANDES (Proposta, 1996), as suas recomendações partiram do conceito de um "padrão unitário de qualidade" visando a corrigir uma "situação em que prolifera o ensino de má qualidade em estabelecimentos que não oferecem aos professores e alunos as condições mínimas para um trabalho acadêmico de bom nível". A proposta da ANDES incluía, entre outros, três princípios fundamentais:

- ensino público, gratuito, democrático, laico e de qualidade para todos;

- autonomia didático-científica, administrativa e de gestão financeira; e

- indissociabilidade entre ensino, pesquisa e extensão.

Os três princípios foram incorporados na Constituição Federal de 1988 que estabeleceu, em seu art. 206, a gratuidade do ensino público e, no art. 207, que as universidades gozassem de autonomia técnico-científica, administrativa e de gestão financeira e patrimonial, obedecendo ao princípio da indissociabilidade entre ensino, pesquisa e extensão.

Ainda graças ao trabalho das sociedades científicas, a Constituição Federal de 1988 incluiu também, em seu art. 218, a autorização para que estados e Distrito Federal vinculassem parcela de sua receita orçamentária a entidades públicas de fomento ao ensino e à pesquisa científica e tecnológica, criando condições para se reproduzir em cada unidade da Federação o modelo Fapesp, que vinha dando excelentes resultados em São Paulo.

\section{A década de 90}

Nos anos 90 o ensino superior apresentou considerável expansão, mas vem enfrentando dificuldades que afetam a sua eficácia e qualidade. O número de instituições passou de 918 para $1.097 \mathrm{com}$ as universidades privadas aumentando de 40 para 83 , e as públicas de 55 para 72 . As 72 universidades públicas estão bem distribuídas entre as cinco regiões; mas, das universidades privadas, $85 \%$ estão concentradas nas regiões Sudeste e Sul. Entre as outras 942 instituições, há 39 "centros universitários", 74 "faculdades integradas", 813 "faculdades" e 16 "centros de educação tecnológica" (MEC, www.mec.gov.br), conforme demonstrado no quadro 1. Das 1.097 instituições, em média 37,3\% localizam-se nas capitais dos estados e $62,7 \%$ no interior, mas com grandes variações (2).

\section{Matrículas e corpo docente}

O total de matrículas em 1999 foi 2.369.945, 64,9\% em instituições privadas (quadro 2). As universidades respondem por $68,3 \%$ das matrículas, quase a metade $(44,8 \%)$ em universidades públicas, mas, nas outras instituições, as públicas dão conta de apenas 14,3\%. Ocorre porém grande variação entre regiões e, dentro destas, entre estados. No Norte as instituições públicas respondem por 
$64,7 \%$, das matrículas, no Nordeste $67,9 \%$ e no Sudeste, $23,3 \%$; enquanto as universidades públicas do Nordeste dão conta de $62,4 \%$ do total, no Sudeste elas respondem por apenas 19,3\% e, no estado de São Paulo, por 11,5\%.

Quadro 1. Número de Instituições de Ensino Superior (1999)

\begin{tabular}{|c|c|c|c|c|c|c|c|c|c|c|c|c|c|c|c|}
\hline \multirow{3}{*}{ Região } & \multicolumn{7}{|c|}{ Universidades } & \multicolumn{7}{|c|}{ Outros } & \multirow{3}{*}{$\begin{array}{l}\bar{\pi} \\
\frac{0}{0} \\
0 \\
\frac{\pi}{0} \\
\end{array}$} \\
\hline & \multicolumn{4}{|c|}{ Públicas } & \multicolumn{3}{|c|}{ Privadas } & \multicolumn{4}{|c|}{ Públicas } & \multicolumn{3}{|c|}{ Privadas } & \\
\hline & $\mathrm{F}$ & $E$ & $M$ & $\mathrm{~T}$ & $P$ & $\mathrm{C}$ & $\mathrm{T}$ & $\mathrm{D}$ & $E$ & $M$ & $\mathrm{~T}$ & $P$ & $\mathrm{C}$ & $\mathrm{T}$ & \\
\hline Norte & 6 & 2 & 0 & 8 & 1 & - & 1 & 1 & 1 & 1 & 3 & 23 & 7 & 30 & 42 \\
\hline Nordeste & 10 & 12 & 0 & 22 & 3 & 3 & 6 & 5 & 4 & 14 & 23 & 63 & 27 & 90 & 141 \\
\hline Sudeste & 13 & 7 & 1 & 21 & 12 & 37 & 49 & 11 & 14 & 30 & 55 & 278 & 231 & 509 & 634 \\
\hline Sul & 6 & 6 & 2 & 14 & 8 & 14 & 22 & 3 & 11 & 5 & 19 & 53 & 40 & 93 & 148 \\
\hline Centro-Oeste & 4 & 3 & - & 7 & 2 & 3 & 5 & 1 & 12 & 7 & 20 & 83 & 17 & 100 & 132 \\
\hline Total & 39 & 30 & 3 & 72 & 26 & 57 & 83 & 21 & 42 & 57 & 120 & 500 & 322 & 822 & 1097 \\
\hline
\end{tabular}

$F=$ Federal $\quad E=$ Estadual $\quad M=$ Municipal $\quad T=$ Total

Quadro 2. Número de matrículas em Instituições de Ensino Superior Em nivel de graduação (1999)

\begin{tabular}{|c|c|c|c|c|c|}
\hline \multirow{2}{*}{ Região } & \multicolumn{2}{|c|}{ Universidades } & \multicolumn{2}{|c|}{ Outros } & \multirow{2}{*}{$\begin{array}{l}\text { Total } \\
\text { geral }\end{array}$} \\
\hline & Públicas & Privadas & Públicas & Privadas & \\
\hline Norte & 56.292 & 10.922 & 4.818 & 22.379 & 94.411 \\
\hline Nordeste & 223.495 & 62.117 & 19.567 & 52.656 & 357.835 \\
\hline Sudeste & 242.714 & 525.684 & 50.717 & 438.447 & 1.257 .562 \\
\hline Sul & 143.879 & 240.963 & 23.095 & 65.199 & 473.136 \\
\hline Centro-Oeste & 58.802 & 54.866 & 8.643 & 64.690 & 187.001 \\
\hline Total & 725.182 & 894.552 & 106.840 & 643.371 & 2.336 .945 \\
\hline
\end{tabular}

Os docentes de ensino superior (quadro 3), 173.836 em 1999, estão igualmente repartidos entre instituições públicas e privadas e sua distribuição regional reproduz aproximadamente a das matrículas.

Nas universidades públicas $77,4 \%$ dos docentes trabalham em tempo integral contra 19,8\% nas universidades privadas. Dos docentes que não estão em tempo integral, 60.228 são "horistas", 91,7\% nas instituições privadas. Há apenas 2.258 horistas em universidades públicas concentradas nas regiões Nordeste (12\%), Sudeste $(35 \%)$ e Sul $(53 \%)$. 
Quadro 3. Funções docentes por regime de trabalho em Universidades e em outras Instituições de Ensino Superior (1999)

\begin{tabular}{|l|c|c|c|c|}
\hline \multirow{2}{*}{ Item } & \multicolumn{2}{|c|}{ Universidades } & \multicolumn{2}{c|}{ Outras } \\
\cline { 2 - 5 } & Públicas & Privadas & Públicas & Privadas \\
\hline$N^{\circ}$ docentes & 73.122 & 51.658 & 7.761 & 41.295 \\
\hline Tempo integral & $77,4 \%$ & $19,8 \%$ & $39,1 \%$ & $9,2 \%$ \\
\hline Tempo parcial & $19,5 \%$ & $25,3 \%$ & $25,4 \%$ & $25,7 \%$ \\
\hline Horistas & $3,1 \%$ & $54,9 \%$ & $35,5 \%$ & $65,1 \%$ \\
\hline
\end{tabular}

Do total de docentes $29,2 \%$ tem mestrado e 20,1\% doutorado. Dos demais, $34,6 \%$ tem cursos de especialização e $16 \%$ apenas graduação, além de um pequeno grupo da ordem de $0,04 \%$ que não chegou a graduar-se (quadro 4 ). Universidades públicas e privadas se igualam com $30,6 \%$ e 30,1\% de docentes com mestrado, mas para doutorado, os índices são de 33,3\% e 12,6\%. As outras instituições de ensino superior seguem o mesmo padrão, mas com percentuais mais baixos que os das universidades. O número de matrículas por docente é bastante uniforme variando entre os limites de 13,1 para o Sul e 14,5 para o Centro-Oeste. A média para o Brasil é 13,5, com 16,5 para instituições privadas e 10,3 para públicas. Estes valores se mantêm com bastante regularidade nos estados mas com algumas exceções como Pará, Sergipe, Bahia e Mato Grosso do Sul, que alcançam entre 20 e 27 nas universidades privadas. Nas universidades públicas o máximo ocorre no Amapá, com 20,2, e o mínimo em São Paulo, com 7,3. Nos outros institutos de ensino superior há maior dispersão, chegando-se a mais de $40 \mathrm{em}$ centros de educação tecnológica.

Quadro 4. Funções Docentes por Grau de Formação em Unversidades e em Outras Instituições de Ensino Superior (1999)

\begin{tabular}{|l|c|c|c|c|}
\hline \multirow{2}{*}{\multicolumn{1}{|c|}{ Item }} & \multicolumn{2}{c|}{ Universidades } & \multicolumn{2}{c|}{ Outras } \\
\cline { 2 - 5 } & Públicas & Privadas & Públicas & Privadas \\
\hline $\mathrm{N}^{\circ}$ de docentes & 73.122 & 51.658 & 7.761 & 41.295 \\
\hline Com Doutorado & $33,3 \%$ & $12,6 \%$ & $12,6 \%$ & $8,1 \%$ \\
\hline Com Mestrado & $30,7 \%$ & $30,2 \%$ & $23,6 \%$ & $26,6 \%$ \\
\hline C/Especialização & $20,5 \%$ & $40,0 \%$ & $46,8 \%$ & $50,3 \%$ \\
\hline Só Graduação & $15,5 \%$ & $17,2 \%$ & $17,0 \%$ & $15,0 \%$ \\
\hline Sem Graduação & $0,03 \%$ & $0,02 \%$ & $-\cdots$ & $0,04 \%$ \\
\hline
\end{tabular}




\section{Cursos de graduação}

O ensino superior oferece 8.878 cursos de graduação, 39,4\% em instituições públicas. Do total de cursos dois terços têm sido dados por universidades, pouco mais da metade por universidades públicas (quadro 5). Nas universidades privadas eles concentram-se nas regiões Sudeste e Sul, enquanto nas universidades públicas 54\% correspondem a Norte, Nordeste e Centro-Oeste.

Quadro 5. Cursos de Graduação (1999)

\begin{tabular}{|l|c|c|c|c|c|c|c|}
\hline \multirow{2}{*}{ Regiōes } & \multicolumn{2}{|c|}{ Universidades } & \multicolumn{2}{c|}{ Outros } & \multicolumn{3}{c|}{ Total } \\
\cline { 2 - 8 } & Pública & Privada & Pública & Privada & Pública & Privada & Geral \\
\hline Norte & 351 & 19 & 20 & 95 & 371 & 114 & 485 \\
\hline Nordeste & 1.003 & 146 & 77 & 241 & 1.080 & 387 & 1.467 \\
\hline Sudeste & 850 & 1.363 & 205 & 1.733 & 1.055 & 3.096 & 4.151 \\
\hline Sul & 557 & 1.076 & 94 & 288 & 651 & 1.364 & 2.015 \\
\hline Centro-Oeste & 284 & 132 & 53 & 291 & 337 & 423 & 760 \\
\hline Brasil & 3.045 & 2.736 & 449 & 2.648 & 3.494 & 5.384 & 8.878 \\
\hline
\end{tabular}

\section{Pós-Graduação}

Dos 1.298 programas de pós-graduação existentes em 1998 (3), 91\% são oferecidos por instituições públicas, 59\% delas federais e 31,9\% estaduais; 68,6\% dos programas em instituições públicas e $73,3 \%$ em instituições privadas estão na região Sudeste (4), conforme demonstrado no quadro 6.

Quadro 6. Distribuição dos Programas de Pós-Graduação

\begin{tabular}{|l|c|c|c|c|c|}
\hline \multirow{2}{*}{ Região } & \multirow{2}{*}{$\begin{array}{c}\text { Número de } \\
\text { Programas }\end{array}$} & \multicolumn{4}{|c|}{$\begin{array}{c}\text { Distribuição por status jurídico da } \\
\text { Instituição de Ensino Superior (em \%) }\end{array}$} \\
\cline { 3 - 6 } & & Federal & Estadual & Particular & Total \\
\hline Norte & 28 & 2,2 & -- & -- & 2,2 \\
\hline Nordeste & 185 & 13,3 & 0,8 & 0,1 & 14,2 \\
\hline Sudeste & 799 & 25,8 & 29,2 & 6,5 & 61,5 \\
\hline Sul & 217 & 12,7 & 1,9 & 2,2 & 16,8 \\
\hline Centro-Oeste & 69 & 5,1 & - & 0,2 & 5,3 \\
\hline Brasil & 1.298 & 59,2 & 31,9 & 9,0 & 100,0 \\
\hline
\end{tabular}


Esses 1.298 programas contam com 14,060 professores, $96,5 \%$ dos quais com doutorado, e com 47.271 alunos de mestrado e 24.250 de doutorado, $84,2 \%$ destes na região Sudeste (quadro 7).

Quadro 7. Alunos matriculados, alunos titulados e docentes em Programas de Pós-Graduação (1997)

\begin{tabular}{|l|r|r|r|r|r|r|}
\hline \multirow{2}{*}{ Região } & \multicolumn{2}{|c|}{ Alunos matriculados } & \multicolumn{2}{c|}{ Alunos titulados } & \multicolumn{2}{c|}{ Docentes } \\
\cline { 2 - 7 } & \multicolumn{1}{c}{$\mathrm{Me}$} & \multicolumn{1}{c|}{ Do } & \multicolumn{1}{c|}{ Me } & \multicolumn{1}{c|}{ Do } & Total & \multicolumn{1}{c|}{ Do } \\
\hline Norte & 751 & 123 & 138 & 19 & 155 & 152 \\
\hline Nordeste & 4.838 & 823 & 1.320 & 108 & 1.728 & 1.592 \\
\hline Sudeste & 31.740 & 20.420 & 7.693 & 3.149 & 9.534 & 9.196 \\
\hline Sul & 8.160 & 2.436 & 2.157 & 285 & 2.091 & 1.969 \\
\hline Centro-Oeste & 1.782 & 448 & 617 & 43 & 552 & 534 \\
\hline Total & 47.271 & 24.250 & 11.925 & 3.604 & 14.060 & 13.443 \\
\hline
\end{tabular}

Dos 127 programas, 83\% são da região Sudeste e oferecem “padrão internacional de excelência" (avaliação 7 e 6). Outros 422 enquadram-se no "critério para curso "A" (avaliação 5 ou mais).

\section{Custos do Ensino Superior}

Um dos grandes problemas enfrentados pelas instituições de ensino superior, que interferem seriamente com a obediência ao instituído na Constituição de 1988 quanto ao desempenho de atividades de ensino, pesquisa e extensão é a escassez de recursos financeiros que afeta tanto as universidades públicas como as particulares e comunitárias (Carvalho da Silva, 2001).

É difícil estabelecer valores precisos para os recursos destinados pelo governo federal às suas instituições de ensino superior. Na composição e interpretação desses valores podem ser computados, além do salário dos docentes e funcionários ativos, o salário dos inativos, recursos do tesouro para outros custeios e capital (OCC), precatórios, convênios, hospitais de ensino etc.

Acrescentem-se ainda as dificuldades e incertezas na correção dos valores para a inflação até 1994 e, no caso de comparações com o exterior, as variações no valor da moeda.

Resulta que cada publicação apresenta dados diferentes de acordo com os componentes que inclui e as correções que são feitas. Os seguintes valores (Amaral, 1999) para o período 1995-1999 podem ser citados como exemplo (quadro 8): 
A julgar por estes valores, entre 1995 a 1999 houve uma redução de 17,3\% nos gastos com as instituições federais de ensino superior e de $22,8 \%$ em sua participação no PIB, contrastando com o aumento de $17,9 \%$ na oferta de vagas e de $20,4 \%$ no número de matrículas.

Quadro 8. Recursos do tesouro aplicados nas IFES.

Valores em milhões de reais a preços de janeiro de 1999 (JGPD, FGV)

\begin{tabular}{|c|c|c|}
\hline \multirow{2}{*}{ Ano } & \multicolumn{2}{|c|}{ Gastos com Instituições de Ensino Superior } \\
\cline { 2 - 3 } & R\$ milhões & \% do PIB \\
\hline 1995 & 6.627 & $0,79 \%$ \\
\hline 1996 & 5.950 & $0,69 \%$ \\
\hline 1997 & 5.897 & $0,66 \%$ \\
\hline 1998 & 5.877 & $0,64 \%$ \\
\hline 1999 & 5.478 & $0,61 \%$ \\
\hline
\end{tabular}

Em sua análise dos custos das universidades federais Durham (1998) destaca, entre outros, três problemas:

- alto custo por aluno e sua grande variação entre universidades sem relação com as qualificações em pesquisa e em ensino de graduação e pós-graduação;

- considerável variação no valor do salário médio dos docentes;

- participação dos inativos em cerca de um terço da folha de pagamento e com salários maiores que os dos docentes em atividade.

O custo médio por aluno depende dos componentes incluídos entre os recursos atribuídos à instituição. Na análise de Durham para 1998 eles variam entre R\$ 17.130 se incluídos custos com inativos e precatórios; R 13.208 se for excluído o pagamento dos inativos; e R 12.262 se também forem excluídos os precatórios. Mesmo aceitando este último valor, argumenta-se que o nosso custo médio é muito alto, quando comparado com o de países mais desenvolvidos. Em 1994, Estados Unidos, Canadá, Reino Unido, Suíça e Japão estavam numa faixa entre US\$ 10.370 e US\$ 12.900 e 11 outros países da Europa e dois do Pacífico (5) apresentavam valores entre US\$ 3.770 para Espanha e US\$ 8.720 para Noruega. Todavia é necessário levar em conta o quanto as comparações com outros países são influenciadas por nossa política cambial. Ao câmbio atual, ao redor de R \$2,20 por dólar, o custo médio por aluno nas universidades federais pode ser comparado com a média de US\$ 6.763 para os países da Europa e do Pacífico. Acresce-se que os valores altos para as nossas IES resultam, em parte, de um grande número de unidades de pequeno alunato. Em 1998 a média para 12 universidades (6), 
com atividade em pesquisa e pós-graduação que eram responsáveis por $53 \%$ dos alunos de graduação nas universidades federais foi de $\mathrm{R} \$ 8.754$, equivalente a cerca de US\$ 3.979. Em contraste, ainda em 1998, 13 centros e faculdades isoladas, que somavam apenas $3,35 \%$ do alunato, tiveram um custo médio por aluno de R\$2 20.707 (U\$ 9,412), sem incluir o gasto com inativos e precatórios.

É surpreendente que, apesar de o princípio da isonomia, a remuneração média dos docentes das instituições federais apresente considerável variação, chegando a valores de $34 \%$ a $136 \%$ acima da média geral em quatro IES. Surpreende também que, em média, o salário dos inativos, que soma um terço dos recursos, seja 1,4 vezes maior que a dos que estão em exercício, chegando essa diferença a valores que vão de 1.6 a 2.4 vezes, em nove instituições. $\mathrm{E}$, como diferenças dessa natureza ocorrem indistintamente em instituições que estão em níveis diversos de atividade em pesquisa e pós-graduação, é pouco provável que elas resultem de diferenças no regime de trabalho ou na titulação acadêmica. No entender de Durham, elas resultam mais de decisões judiciais divergentes e benefícios corporativos, razões que nada têm a ver com o mérito didático e científico.

Quanto às universidades estaduais, elas estão sob duas grandes formas de financiamento. Em pelo menos quatro estados a dotação corresponde a um percentual da renda dos impostos. Esta dotação pode ser adequada, como acontece em São Paulo e Santa Catarina; elevada, mas não integralmente cumprida, como na Universidade Estadual do Rio de Janeiro; insuficiente, mas suplementada, como na Fundação Universidade Estadual de Pernambuco. De qualquer modo a vinculação assegura maior estabilidade e autonomia embora possa resultar em dotação insuficiente nos períodos de crise econômica. Nas universidades estaduais em que não existe vinculação, e que constituem a grande maioria, são necessários, ano a ano, entendimentos com governos do estados e assembléias legislativas para se conseguir um mínimo compatível com algum desenvolvimento ou mesmo para a sobrevivência da instituição. Na liberação dos recursos é quase sempre respeitada a quota destinada a pessoal mas, apesar disso, a Universidade Estadual de Alagoas interrompeu por oito meses o pagamento de salários em virtude da crise econômica do estado. A escassez e as incertezas do orçamento afetam a contratação de novos docentes e a oferta de salários adequados na grande maioria das universidades estaduais, embora se alegue que nas do Ceará e de Pernambuco os valores cheguem a ser iguais ou maiores que nas das federais (Sampaio et al., 1998).

Duas universidades estaduais - Pernambuco e Tocantins - cobram mensalidade. Essa cobrança pode ser considerada inconstitucional mas procura-se justificá-la por se tratar de fundações de direito privado e vem sendo defendida pela administração de outras universidades estaduais como condição para expansão, elevação dos vencimentos do corpo docente e criação de condições para pósgraduação e pesquisa. 
Não se dispõe de dados precisos para quantificar a participação dos estados no financiamento do ensino superior público no país, mas pode-se afirmar que ela é considerável. Só o estado de São Paulo no ano 2000, sem contar a Fapesp, investiu nas três universidades estaduais cerca de R $\$ 2$ bilhões, correspondendo a aproximadamente um terço do investimento do MEC em todas as instituições federais.

Nas instituições privadas (Schwartzman, 1998) a mensalidade dos alunos atende, em média, a 95\% dos custos nas particulares e a $80 \%$ nas comunitárias. Onde existem hospitais de ensino, estes podem acarretar prejuízos ou trazer lucro, dependendo da proporção entre o atendimento a pacientes cobertos pelo SUS e por convênios de saúde. Outras fontes de recursos como contratos com governo e empresas, matrículas em pós-graduação, transferência de recursos da União ou saldo líquido do exame vestibular são, em geral, pouco significativas. Auxílios da Finep e bolsas de Capes e CNPq somam, em alguns casos, recursos mais significativos mas que em geral são canalizados diretamente para o aluno ou para o pesquisador.

Problema particularmente grave nas instituições privadas refere-se à inadimplência, difícil de ser controlada porque não se pode proibir a freqüência aos cursos e nem recusar documentação para transferência. Entre as soluções desenvolvidas estão as matrículas parciais por crédito e o programa do crédito educativo do governo ou da própria instituição. O MEC oferece, atualmente, um "Financiamento Estudantil" (FIES), cobrindo até 70\% da mensalidade, reembolsável após a formatura em um período 1,5 vezes a duração do curso, com juros de $9 \%$ ao ano. Algumas instituições privadas mantêm programas que podem cobrir o pagamento integral da mensalidade. Em geral exige-se fiador e um reembolso após a formatura em período igual à duração do curso. O nível usual do reembolso é da ordem de R $\$ 40$ mil a R\$ 50 mil, mas em curso de Medicina pode ultrapassar R\$ 120 mil.

\section{Autonomia, avaliação}

A autonomia da universidade pública, assegurada pela Constituição Federal de 1998, dá origem a um debate em que se entrelaçam forma e volume da dotação orçamentária, carreira docente, isonomia salarial, estabilidade e direitos adquiridos de pessoal ativo e inativo, capacidade em pesquisa e pós-graduação etc.

A ANDES defende a autonomia como um dos princípios norteadores à implantação do Padrão Unitário de Qualidade para a universidade brasileira. No seu entender, a autonomia prevista na Constituição é auto-aplicável mas, face às interpretações jurídicas discordantes, oferece um projeto próprio (7).

A Emenda Constitucional 370 (1996), com substitutivo da Comissão Especial, mantém a redação do art. 207, definindo aspectos da autonomia didáticocientífica e da gestão financeira e patrimonial, assegurando o orçamento global e 
propondo um Fundo de Manutenção e de Desenvolvimento do Ensino Superior formado por $75 \%$ dos recursos vinculados à educação (Fonte 112), a serem transferidos às instituições, em duodécimos, até o dia 20 de cada mês (8), sendo vedada a sua utilização para o pagamento de aposentadorias e pensões. A duração do Fundo será de 10 anos e $5 \%$ serão destinados à expansão do sistema público de ensino superior. Prevê-se também que, no mínimo, de 7,5\% dos recursos vinculados à educação sejam destinados ao credito educativo (9).

Na análise de Schwartzman (1996; 1998) a Emenda 370 não resolve problemas atuais controversos como estabilidade, isonomia salarial e piso mínimo de vencimentos e cria a indesejável convivência de dois regimes de trabalho. Os recursos previstos (75\% da Fonte 112) não serão suficientes para um reajuste de salários que compense a inflação durante o Plano Real e preenchimento de 7.767 vagas de docentes e 17.315 de servidores.

Durham (1993) recomenda que antes de se estabelecer a autonomia se desmonte a carreira docente atual e se estabeleça um modelo baseado no mérito com perspectivas de aumento salarial associado a responsabilidades e obrigações bem definidas; que se dê solução ao problema das aposentadorias; que se criem condições que inibam a aposentadoria precoce; que se estabeleça um piso salarial uniforme mas que os salários sejam decididos em cada instituição, em função dos seus recursos; e que um percentual do orçamento esteja vinculado a indicadores de desempenho tais como número de alunos por docente, avaliação da graduação por comissões de especialistas, pós-graduação, volume e qualidade da produção científica etc.

Ante tantas dificuldades e a intransigência dos setores envolvidos, Trindade (1999) sugere que se implante a autonomia apenas em algumas universidades por uns cinco ou dez anos e se tomem decisões posteriores com base na experiência adquirida.

Outra fonte de conflitos diz respeito às justificativas para serem concedidos recursos com base no mérito da instituição. Para muitas lideranças acadêmicas a subordinação dos recursos a indicadores de produtividade, entre outros, número de publicações, número de alunos e de alunos por docente, cursos de pós-graduação (Schwartzman, 1994), representam uma visão empresarial de rentabilidade imediata do investimento em educação; a universidade deixa de ser uma "instituição social" para se converter em uma "organização" com metas de produção de resultados e prestação de serviços como qualquer empresa (Chauí, 1999). Segundo as propostas da ANDES, deve haver uma "avaliação interna" visando a análise e reformulação da política de cada unidade de ensino em que se explicitem condições para o seu desenvolvimento pleno e uma "avaliação externa" a cargo de um Conselho Social autônomo que, levando em conta as prioridades dos diferentes setores da Sociedade, proponha rumos para a política de ensino, pesquisa e extensão, e avalie o seu desempenho. 
Apesar de as controvérsias quanto a forma e objetivos da avaliação, ela já vem sendo conduzida com reflexos positivos sobre o desempenho institucional, como é o caso da Universidade Federal de Pernambuco (Fittipaldi, 2001).

Também a "indissociabilidade de ensino-pesquisa-extensão", estabelecida no art. 207 da Constituição dificilmente pode ser atendida no presente por grande parte das universidades, porque não reúnem condições para desenvolver pesquisa em volume e qualidade razoáveis, e nem poderão consegui-las a curto e mesmo a médio prazo. A criação de condições para que todas as universidades possam desenvolver uma atividade em pesquisa que contribua para elevar a qualidade do ensino, para o desenvolvimento da ciência e para o progresso sócio-econômico da região a que estão vinculadas implica formar e manter um corpo docente com avançado nível de treinamento e dispor de recursos para formar bibliotecas, equipar laboratórios e financiar os custos da investigação científica. A criação destas condições exige prazos bastante longos e recursos consideráveis a serem oferecidos pelo governo federal e dos estados, pelos fundos setoriais em processo de implantação e pelas fundações e fundos estaduais de amparo à pesquisa, desde que estes recebam dos estados os recursos que lhes são devidos. Para que a obediência à Constituição seja real e não uma simulação seria mais acertado converter muitas das atuais universidades em “Centros Universitários” e dar-lhes o apoio necessário para que pudessem, no futuro, reverter a condição presente.

\section{Oferta de vagas}

A pressão por vagas em ensino superior aumentou consideravelmente na década de 90 (Carvalho da Silva, 2001). Em 1980 o excesso de inscritos no vestibular em relação ao número de vagas foi 1.500.684; em 1990, $1.402 .714 \mathrm{e}$ em 1999, 2.449.883. De 1980 a 1990 o número de candidatos inscritos em vestibular aumentou apenas em 5,7\%, mas passou de 1.905 .498 em 1990 para 3.334.273 em 1999, um aumento de 75\%. Nos mesmos períodos o número de vagas aumentou $15,3 \%$ e $77,9 \%$. Das 894.390 vagas em 1999, 218.589 (24,4\%) eram em instituições públicas e a elas se candidataram 1.806.208 inscritos em vestibular (8,26 candidados/vaga) enquanto para as 675.821 oferecidas por instituições privadas se inscreveram 1.538 .086 candidatos (2,76 candidatos/vaga). De acordo com esses dados, um programa de aumento de vagas que leve em conta a natureza da procura deverá se concentrar nas instituições públicas, particularmente em suas universidades que, em 1998, atraíram 79,7\% dos candidatos ao ensino público.

Além de a dependência administrativa, tanto a oferta de vagas quanto o número de candidatos inscritos variam bastante segundo a região e a área de conhecimento. Por região, em 1999 a oferta de vagas em ensino superior foi de 1,92 por mil habitantes no Norte, 1,99 no Nordeste, 6,89 no Sudeste, 5,79 no Sul e 5,10 no Centro-Oeste (10). Por área de conhecimento, em 1998 predo- 
minaram ciências sociais aplicadas, com $42,5 \%$ das vagas, e humanas, com 15,4\%, seguidas por exatas e da terra, 11,9\%; saúde, 11,3\%; lingüística e artes, 7\%; agrárias, $2,4 \%$; e biológicas, $2 \%$. A distribuição dos inscritos em vestibular foi bastante próxima, menos para saúde com $23,1 \%$ e lingüística, letras e artes com $4,1 \%$.

As diferenças entre áreas de conhecimento na relação candidato/vaga são evidentes na Universidade de São Paulo (Anuário Estatístico, 1999) onde no vestibular de 1998 para 121 cursos, os extremos foram 80,5 candidatos por vaga no curso de publicidade e propaganda matutino e 0,8 no curso de grego noturno; a média para 15 cursos da ECA foi 30,7 e para 39 cursos da FFLCH, 4.

A distribuição por área de conhecimento escolhida pelos candidatos na inscrição para exame vestibular pode não traduzir fielmente as suas preferências profissionais, científicas ou culturais. Pode ocorrer que eles optem por áreas em que o número de vagas é maior e há menos concorrência para terem maior probabilidade de sucesso. A análise dos dados da Fuvest para a USP em 1997 (Pinho, 2000 ) apóia essa interpretação. Um conjunto de opções disciplinares foi dividido em dois subconjuntos: o primeiro, classificado como A, incluindo Medicina, Direito, Engenharia e Ciências Exatas; o segundo, como B, englobando as carreiras oferecidas pela FFLCH - Ciências Sociais, Filosofia, Geografia, História, Letras e bacharelado em Física. No subconjunto A, altamente competitivo, 21,7\% dos inscritos vinham de escola pública estadual e $60,9 \%$ de ensino privado (11); no subconjunto $\mathrm{B}$, em que há menor competição e maior probabilidade de sucesso, $48 \%$ dos inscritos vinham de escolas públicas estaduais e $35 \%$ de escolas privadas. Esses dados sugerem que os alunos de escolas públicas, sentindo-se menos preparados para enfrentar a forte competição no subconjunto $A$, optam pelo $B$ no qual há maior probabilidade de sucesso.

Mantidas as proporções atuais entre ensino público e privado, será necessário um aumento anual de vagas de $10 \%$ sobre o ano anterior, bem acima do ritmo de aumento nos últimos dez anos (12), para atingir nos próximos sete a oito anos um número de matrículas ao redor de $20 \%$ na faixa etária 18 a 24 anos (13).

Se o ritmo de aumento no ensino privado diminuir, serão necessários aumentos maiores no ensino público chegando-se a cerca de $15 \%$ ao ano sobre o ano anterior se se pretender atingir cerca de cinco milhões de matrículas por volta de 2010 ou 2011 e o número de matrículas no ensino privado se fixar nos atuais 1,5 milhões. É interessante destacar que nem este nível de aumento de vagas atenderia a todas as reivindicações. Por exemplo, o Plano Nacional de Educação (PNE), elaborado por setores organizados da sociedade civil (entidades acadêmicas sindicais e estudantis, setores da administração pública e parlamentares progressistas) estabelece como meta para os próximos dez anos, estender o ensino superior público a $40 \%$ da população na faixa etária de 18 a 24 anos (Bollmann, 1998). 
Uma possível solução para evitar aumentos tão acelerados nas universidades públicas seria oferecer matrícula nas instituições públicas isoladas aos candidatos aprovados em vestibular nas universidades mas que não consigam vaga. O número de institutos isolados e o corpo docente deveriam ser consideravelmente aumentados, abrindo-se oportunidades de trabalho como docente para os que concluem a pós-graduação. Esta solução combina com o fato de que das 120 unidades públicas isoladas existentes em 1999, 74 estão no Sudeste e Sul onde é maior a procura por vagas e onde também se concentra a pós-graduação que poderia ser a grande fonte de novos docentes.

Tem-se considerado também concentrar o aumento do número de vagas em universidades menos produtivas em pós-graduação e pesquisa como forma de proteger as instituições de maior destaque nessas atividades. Essa política discriminatória justificar-se-ia como solução de emergência para preservar alguns centros de excelência em pesquisa e pós-graduação, essenciais ao desenvolvimento e dos quais o país não pode prescindir.

Às propostas de aumento de vagas nos cursos tradicionais cabe acrescentar: a criação de novos cursos; o melhor aproveitamento de recursos já existentes como, por exemplo, o preenchimento de vagas decorrentes da evasão e a ocupação alternativa de vagas em outras unidades, no mesmo conjunto disciplinar; o aumento das quotas de vagas em curso noturno; e o uso do ensino a distância e outras técnicas inovadoras (Cortelazzo, 2001).

Por fim, cabe considerar até que ponto seria viável aumentar anualmente, durante oito a dez anos, entre $10 \%$ e $15 \%$ ao ano sobre o ano anterior o número de vagas nas universidades públicas em geral, mas sem prejuízo da qualidade da pesquisa e do ensino superior em seus dois níveis. Entre as medidas que seriam necessárias podem ser citadas:

- assegurar autonomia didático-científica, administrativa e financeira e dotação global às universidades públicas para que possam ajustar o número de docentes e pessoal de apoio, salários, regime de trabalho e outras fontes de despesas aos recursos disponíveis;

- excluir da dotação global salários e benefícios dos aposentados, custos de hospitais de ensino etc.;

- além da dotação global cujo valor deve ser calculado na base do desempenho em ensino de graduação e pós-graduação, pesquisa, extensão e prestação de serviços, estabelecer um fundo federal e fundos estaduais e municipais para suplementar a dotação global de cada universidade em função de seus planos plurianuais de expansão de ensino e pesquisa.

- criar incentivos que estimulem as empresas a investir em projetos de pesquisa com universidades; 
- além da contribuição esperada dos fundos setoriais, recuperar a capacidade de fomento do CNPq e das fundações e fundos estaduais de amparo à pesquisa nos níveis em que foram estabelecidos nas constituições de cada unidade da Federação ou, pelo menos, em níveis estáveis e compatíveis com uma contribuição para o desenvolvimento da pesquisa no estado.

\section{Ensino público pago?}

Embora o custo médio por aluno deva diminuir com aumentos de vagas dessa magnitude, o custo do ensino superior público deverá aumentar substancialmente tanto em pessoal quanto em custeio e capital, pondo em risco a sua gratuidade. Com base nesse aumento, vem se intensificando a campanha contra a sua gratuidade apesar de esta ser assegurada pela Constituição Federal. Com uma visão neoliberal alega-se que, ao oferecer o grau superior numa perspectiva de maior renda pessoal, o ensino deve ser visto como um investimento com retornos elevados e, portanto, deve ser pago. Acusa-se ainda a gratuidade de injustiça social por ser elevado o número de estudantes com renda familiar média e alta, em detrimento dos mais pobres que, sendo superados na competição por vagas, acabam por recorrer ao ensino pago.

A meu ver, para um país em desenvolvimento em que a educação em todos os níveis é política social da mais alta prioridade, a visão neoliberal não se aplica e o argumento da injustiça social constitui, de certo modo, uma falácia. Os alunos de menor renda têm menor probabilidade de acesso à universidade pública gratuita em virtude da diferença de qualidade entre ensino básico público e particular e essa diferença vem se agravando. Na Universidade de São Paulo, em 1980, 57\% dos aprovados no vestibular vinham de escolas públicas; em 1993, 32\%; e em 1998, 21\%. O que se torna mais urgente, e socialmente justo, é recuperar a qualidade do ensino público básico para que os seus alunos possam, em condições de igualdade com os de escolas particulares, disputar as vagas nas universidades públicas. Segundo as estatísticas da Fuvest, em São Paulo, em 1997, entre os candidatos às quatro áreas de conhecimento mais disputadas, $24,7 \%$ eram de escolas públicas estaduais e municipais e conquistaram apenas $6,7 \%$ das vagas; $68,4 \%$ eram de escolas particulares e obtiveram $85,7 \%$; mas os $2,3 \%$ vindos de escolas públicas federais conseguiram $4,2 \%$ das vagas, alcançando um índice de aprovação mais alto do que o das particulares, mostrando que os alunos da escola pública nada ficam a dever em talento quando a qualidade do ensino é adequada.

\section{Instituições públicas e o desenvolvimento nacional: necessidade de descentralização}

É fundamental reconhecer que as universidades públicas e institutos públicos de pesquisa, além de manterem 91\% dos programas de pós-graduação, vêm 
dando a principal contribuição para o desenvolvimento científico e tecnológico do país. Na Capes, no ano 2000, os candidatos das instituições públicas deram conta de $85 \%$ das bolsas de mestrado e $90 \%$ das bolsas de doutorado no Brasil e $96 \%$ das bolsas de pesquisa e treinamento no exterior; no CNPq, em 1999, foram vinculados a instituições públicas $87 \%$ das bolsas no exterior, $84 \%$ dos auxílios à pesquisa, 93\% das bolsas de iniciação científica, 96,3\% dos 8.924 núcleos de pesquisa identificados no país e $95 \%$ dos pesquisadores ativos nesses núcleos. Contam também com a participação de instituições públicas $89 \%$ das atividades de pesquisa na empresa apoiadas pela lei de incentivos fiscais, com $72 \%$ delas apoiadas pela lei da informática. No estado de São Paulo, no período de 1994-1999, as universidades públicas e institutos públicos de pesquisa obtiveram 95\% do investimento da Fapesp em auxílios e bolsas; 97\% dos projetos temáticos de equipe; 98\% dos projetos no programa de inovação tecnológica em parceria com empresas; 91\% dos participantes no projeto "Genoma"; 77\% dos projetos em políticas públicas; 97\% dos projetos em apoio da recuperação da infra-estrutura do sistema estadual de ciência e tecnologia. Considerando que a formação e o amadurecimento de um novo centro de pesquisa leva uma ou mais décadas, torna-se fundamental que o atual sistema público de universidades e institutos receba o apoio necessário para que possa dar a sua indispensável contribuição para o desenvolvimento.

Embora a distribuição de universidades públicas seja favorável às regiões Norte, Nordeste e Centro-Oeste, a participação dessas regiões na pesquisa científica e tecnológica está bem abaixo de sua participação na população e no PIB nacional (Carvalho da Silva, 2000), como pode ser visualizado no quadro 9.

Entre as múltiplas iniciativas para se corrigir esse desequilíbrio merecem destaque as Fundações e Fundos de Amparo à Pesquisa previstos nas Constituições de 21 estados e Distrito Federal em 1989, com dotações que vão de 0,3\% a $3 \%$ da arrecadação de impostos. Esperava-se que, a exemplo do que aconteceu em São Paulo com a instalação da Fapesp em 1960, as FAPs e fundos estaduais apoiassem, em cada unidade da Federação, a pesquisa científica e a formação e fixação de pesquisadores criando condições para o desenvolvimento de pesquisa aplicada às prioridades e oportunidades locais, a um custo anual de US\$ $350 \mathrm{a}$ US\$ 400 milhões para todo o país. Passados 12 anos, de seis unidades que vêm mantendo as suas fundações de amparo à pesquisa com regularidade, apenas São Paulo transfere os recursos previstos na Constituição. Nos demais, as transferências variam de ano a ano, baixando às vezes a mínimos de $4 \%$ a $6 \%$ do que deveria ser transferido no ano (Carvalho da Silva, 2000).

O programa de fundos setoriais (Carvalho da Silva, 2000a), como demonstrado no quadro 10, com previsão de um investimento adicional de cerca de R \$ 5 bilhões em cinco anos e com previsões de investimentos em favor de áreas menos desenvolvidas, também poderá contribuir para diminuir o atual desequilíbrio se 
estabelecer forte intercâmbio com as FAPs dessas regiões e se enquadrar na estratégia de fortalecer, em cada estado, a competência básica nas várias áreas do conhecimento em vez de se concentrar apenas em projetos de interesse imediato. A competência local em ciência e tecnologia continua sendo considerada como condição fundamental para a produção e transferência do conhecimento. Embora a dinâmica de desenvolvimento tecnológico e inovação esteja sendo objeto de debate, é consenso que o investimento no desenvolvimento científico e tecnológico local trará retornos elevados no progresso social e econômico da região.

Quadro 9. Distribuição regional de indicadores de riqueza e de Ciência e Tecnologia

\begin{tabular}{|l|c|c|c|c|c|}
\hline \multirow{2}{*}{\multicolumn{1}{|c|}{ Indicador }} & \multicolumn{5}{|c|}{ Região } \\
\cline { 2 - 6 } & Norte & Nordeste & Sudeste & Sul & $\begin{array}{c}\text { Centro- } \\
\text { Oeste }\end{array}$ \\
\hline População \% 1998 & 7,3 & 28,4 & 42,6 & 14,9 & 6,8 \\
\hline PIB (distribuição \%) & 4,4 & 13,0 & 58,5 & 17,7 & 6,4 \\
\hline PIB per capita (1) & 65,5 & 49,9 & 148,7 & 108,0 & $124,0^{(2)}$ \\
\hline Universidades públicas & 10,4 & 28,6 & 27,2 & 24,7 & 9,1 \\
\hline Universidades particulares & 1,3 & 7,9 & 64,4 & 19,7 & 6,7 \\
\hline Cursos de doutorado & 1,2 & 6,6 & 77,3 & 12,1 & 2,8 \\
\hline Artigos científicos exterior & 1,6 & 8,4 & 72,4 & 14,4 & 3,2 \\
\hline $\begin{array}{l}\text { Projetos Aprovados } \\
\text { FNDCT (1986-1996) }\end{array}$ & 2,7 & 11,2 & 68,2 & 12,7 & 5,2 \\
\hline $\begin{array}{l}\text { Auxílios FINEP (1986- } \\
\text { 1996) }\end{array}$ & 0,3 & 7,5 & 70,0 & 19,2 & 3,0 \\
\hline PADCT-II & 1,6 & 8,8 & 67,8 & 16,0 & 5,8 \\
\hline $\begin{array}{l}\text { Instituições com } \\
\text { Núcleos de Excelência }\end{array}$ & 3,7 & 9,9 & 69,1 & 13,6 & 3,7 \\
\hline
\end{tabular}

(1) em \% da média, R\$ 5 mil

(2) excluindo o Distrito Federal, passa a $80 \%$. 
Quadro 10. Fundos Setoriais e estimativa de sua contribuição(1)

\begin{tabular}{|l|c|c|}
\hline \multirow{2}{*}{\multicolumn{1}{|c|}{ Fundo }} & \multicolumn{2}{c|}{ Contribuição esperada (R\$ milhões) } \\
\cline { 2 - 3 } & 2001 & $2001-2005$ \\
\hline Petróleo (CTPetro) & 130 & 720 \\
\hline Infra-estrutura & 200 & 1.160 \\
\hline Informática & 50 & 265 \\
\hline Telecomunicações & 225 & 1.440 \\
\hline Universidade-Empresa (F.Verde-Amarelo) & 240 & 1.320 \\
\hline Energia & 100 & 560 \\
\hline Mineral & 5 & 20 \\
\hline Transportes & 10 & 120 \\
\hline Espacial & - & 80 \\
\hline Recursos Hídricos & 25 & 120 \\
\hline Total & 1.015 & 5.805 \\
\hline
\end{tabular}

(1) Não estão incluídos quatro fundos ainda não aprovados:

Saúde, Aeronáutica, Agronegócios, Biotencologia

\section{Conclusão}

Em síntese, o ensino superior público vem se desenvolvendo satisfatoriamente em pós-graduação e pesquisa mas, além de má distribuição regional, não tem atendido à demanda da Sociedade por vagas em ensino de graduação. Um aumento acelerado de vagas poderá comprometer a qualidade do ensino público superior se não forem tomadas medidas adequadas. Entre elas, alguns propõem o ensino público pago acompanhado de um programa de crédito educativo e de medidas que facilitem às instituições públicas angariar recursos de fontes fora das esferas do governo. Todavia não há indicações do quanto estas medidas poderiam contribuir para assegurar uma ampliação acelerada do número de vagas e o amplo acesso da população de menor renda e, ao mesmo tempo, fortalecer ou ao menos preservar a capacidade em pesquisa e pós-graduação.

De qualquer modo, é essencial a recuperação da qualidade do ensino público fundamental e médio, como condição para que as universidades públicas não se tornem privilégio dos mais abastados. Neste contexto, já de si bastante complexo, destaca-se o problema do financiamento da pesquisa em nível regional. Este deveria ser apoiado, em grande parte, pelas fundações estaduais de amparo à pesquisa, às quais, porém, os governos dos estados não estão transferindo os recursos que lhes são devidos. 
Por trás deste múltiplo cenário estão também as instituições privadas e as sociedades científicas, sindicatos e associações de docentes tomando posições muitas vezes corporativas ou propondo soluções inviáveis.

A exemplo do que ocorreu nos Estados Unidos com a Boyer Commission (Ristoff, 1999), no Reino Unido com o Dearing Report (Sguissardi, 1999) e na França com o Rapport Attali (Trindade, 1999), seria recomendável formar uma comissão de especialistas representando o governo central, as diversas regiões do país e a comunidade acadêmica, para realizar um estudo sobre as condições atuais e propor medidas que sejam viáveis e possam contribuir para formular uma política de ensino superior firmemente integrada com o desenvolvimento científico social, cultural e econômico do país.

Notas

1 Conhecida como "Reforma Francisco de Campos".

2 Por exemplo, 17\% em Belo Horizonte e 18,7\% em Florianópolis.

3601 programas de mestrado, 26 de doutorado e 661 de mestrado/doutorado. Um relatório de abril de 2001 refere 1.460 programas de mestrado e 853 de doutorado.

4 No relatório de 2001 (nota 3) 59,2\% dos mestrados e 69,6\% dos doutorados estão na região Sudeste. A diferença entre os dois relatórios pode ser, em parte, devida a que no relatório de 1998 um programa mestrado/doutorado é contado uma vez e no de 2001, duas vezes.

5 Em dólares norte americanos: Alemanha, US\$ 6.550; Bélgica, US\$ 6.850; Dinamarca, US\$ 6.710; Espanha, US\$ 3.770; França, US\$ 6.020; Holanda, US\$ 8.720; Itália, US\$ 5.850; Áustria, US\$ 5.820; Finlândia, US\$ 8.650; Noruega, US\$ 8.720; Suécia, US\$ 7.120; Austrália, US\$ 6.550; Nova Zelândia, US\$ 6.080 .

6 UFPE, UFBA, UnB, UFSC, UFMG, UFRJ, UFSCAR, UFRS, UFCE, UFPB, UFPA, UFPR.

7 De acordo com o projeto, a autonomia consiste em: fixar diretrizes e meios para o desenvolvimento do ensino, da pesquisa e da extensão; criar, organizar, modificar e extinguir cursos de graduação, pós-graduação e outros; definir o curriculum de seus cursos, observado o que cumpre ao Conselho Nacional de Educação; estabelecer o calendário escolar e o regime de trabalho didático em seus diferentes cursos; estabelecer critérios e normas de seleção, admissão, promoção e transferência de seus alunos; conferir graus, diplomas, certificados e outros títulos acadêmicos, elaborar seus estatutos e regimentos; escolher os seus dirigentes; dimensionar o seu quadro docente e administrativo; administrar privativamente os recursos de dotações orçamentárias globais e regulares, preservada a isonomia salarial; receber subvenções, doações, heranças e legados, celebrar contratos referentes a obras, compras, alienação e concessão etc.; elaborar o orçamento total de sua receita e despesa e definir normas 
e procedimentos para elaboração, execução e controle do orçamento. Sobre as instituições privadas a proposta é de que "gozem de autonomia didática, científica, administrativa e financeira em relação as respectivas mantenedoras nos moldes estabelecidos para as instituições de ensino superior públicas.

8 No substitutivo a transferência se dá à medida em que se realizar a arrecadação dos impostos destinados ao Fundo.

9 O substitutivo suprime esse parágrafo e propõe valor equivalente ao destinado no exercício de 1996 durante os cinco anos seguintes à promulgação da Emenda.

10 Sem DF a relação baixa para cerca de 4 .

11 Além dos dois grupos, fazem parte de cada subconjunto candidatos com histórico misto e candidatos vindos de escolas técnicas federais.

$12 \mathrm{O}$ ritmo de ensino privado pouco tem de aumentar mas o crescimento anual do ensino público terá de ser três a quatro vezes maior do que nos últimos anos.

13 Ao longo dos últimos dez anos uma vaga corresponde a 3,9 matrículas no ensino público e 2,5 no ensino privado.

Referências bibliográficas

AMARAL, Nelson Cardoso. Crise no financiamento das instituições de ensino superior. In: Universidade em ruinas na república dos professores. Petrópolis, Vozes, 1999, p. 191-200.

ANUÁRIO ESTATÍSTICO. São Paulo, Universidade de São Paulo, 1999.

BOLLMANN, Maria da Graça Nóbrega. Apresentação do PNE ao Movimento Docente Nacional. Universidade e Sociedade, v. 6, n. 15, p. 117-153, 1998.

CARVALHO DA SILVA, Alberto. O Instituto de Ciências Biomédicas da USP, 25 anos. CONGRESSO DO INSTITUTO DE CIÊNCIAS BIOMÉDICAS DA UNIVERSIDADE DE SÃO PAUlO, 2. Jubileu de Prata, São Paulo, ICB Publicações, 1997, p. 1-14.

. Descentralização em política de ciência e tecnologia. Estudos Avançados, v. 14, n. 39, p. 61-73, 2000.

Comentários sobre a política nacional de ciência e tecnologia. São Paulo, Sessão Comemorativa do Centenário do Instituto Butantan, 2000a

A oferta de vagas na universidade brasileira. In: Em tempos de greve na universidade pública. Marília, Unesp, Faculdade de Filosofia e Ciências, 2001.

CHAUÍ, Marilena. A universidade em ruínas. In: Universidade em ruínas na república dos professores, Petróplois, Vozes, 1999, p. 211-223.

CORTELAZZO, Ângelo Luiz. In: A USP e seus desafios. Avaliação Institucional. Fórum de Politicas Universitárias. São Paulo, Edusp, 2001, p. 114-123. 
DANTES, Maria Amélia Mascarenhas. Institutos de pesquisa científica no Brasil. In: História das Ciências no Brasil, v. 2. São Paulo, Edusp, EPU, CNPq, 1980.

DURHAM, Eunice Ribeiro. Uma política para o ensino superior brasileiro. Documento de trabalho 1/98. São Paulo, NUPES/USP, 1998.

Uma política para o ensino superior. Documento de trabalho 2/93, São Paulo, NUPES/USP, 1993.

EVOLUÇÃO DO ENSINO SUPERIOR: Graduação, 1980-1998. Brasília, MEC-INEP, 2000.

FERREIRA, José Pelucio. Ciência e tecnologia na América Latina. Reunião de Trabalho, São Paulo, Fapesp, 1993.

FITTIPALDI, Ivon. In: A USP e seus desafios. Avaliação institucional. Fórum de Politicas Universitárias. São Paulo, Edusp, 2001, p. 83-92.

KLEIN, Lúcia. Política e políticas de ensino superior no Brasil. Documento de trabalbo 2/92, NUPES/USP, São Paulo, SP, 1992.

MINISTÉRIO de Educação, Cultura e Desportos. www.mec.gov.br.

O ESTADO ATUAL e o papel futuro de ciência e tecnologia no Brasil. Tema IV. Instituições Governamentais de Ciência e Tecnologia. Estudo 30. Indicadores Quantitativos de Ciência e Tecnologia no Brasil, versão 3.2. Campinas, NPCT/Unicamp e COOE/CNPq, 1994.

PINHO, Alceu G. de. Reflexões sobre o papel do concurso vestibular para as universidades públicas. Série Educação para a Cidadania, São Paulo, IEA-USP, 2000.

PROPOSTA DA ANDES/SN para a universidade brasileira. Brasília, Cadernos ANDES, 1996.

RISTOFF, Divo J. Boyer Commission: O modelo americano em revista. In: Universidade em ruinas na república dos professores, Petrópolis, Vozes, 1999, p. 75-86.

SAMPAIO, Helena; BALBACHEVSKY, Elisabeth \& PEÑALOSA, Verônica. Universidades estaduais no Brasil. Características institucionais. Documento de trabalbo 4/98, São Paulo, NUPES/USP, 1998.

SAMPAIO, Helena. Evolução do ensino superior brasileiro. Documento de trabalho 8/ 95, São Paulo, NUPES/USP, 1991.

SCHWARTZMAN, Jacques. Políticas de ensino superior no Brasil na década de 90. Documento de trabalho 3/96. São Paulo, NUPES/USP, 1996.

Questões de financiamento nas universidades brasileiras. Fortaleza, 63ª Reunião Plenária do CRUB, 1998.

Um sistema de indicadores para as universidades brasileiras. Documento de trabalho 5/94. São Paulo, NUPES/USP, 1994. 
SGUISSARDI, Valdemar. Dearing Report. Novas mudanças na educação superior inglesa. In: Universidade em ruinas na república dos professores. Petrópolis, Vozes, 1999, p. 211-223.

TRINDADE, Hélgio. Autonomia segundo o MEC; fragilidade política e ambigüidade conceitual. In: Universidade em ruinas na república dos professores. Petrópolis, Vozes, 1999, p. 171-176.

Report Attali: Bases da reforma do ensino superior francês. In: Universidade em ruinas na república dos professores. Petrópolis, Vozes, 1999a, p. 87-93.

Alberto Carvalho da Silva, médico, é professor-honorário do Instituto de Estudos Avançados da USP.

Alguns trechos deste artigo constam de outros, em publicações do mesmo autor: Estado atual de ciência e tecnologia no Brasil e A oferta de vagas na universidade brasileira. 